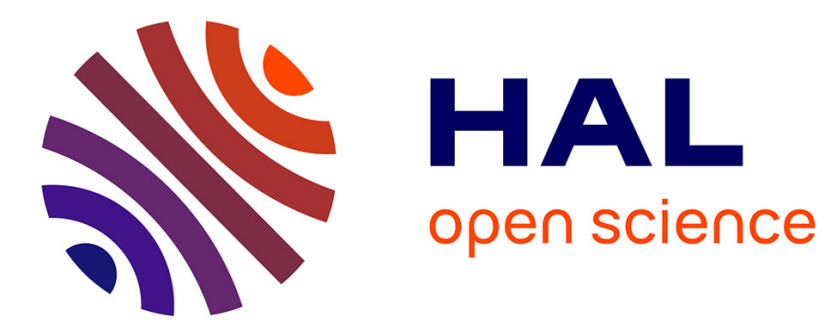

\title{
Structural effects on the emission properties of Pr3+-doped Ba2NaNb5O15 crystals
}

Enrico Cavalli, Gianluca Calestani, Francesco Mezzadri, Raffaele Faoro, Mauro Tonelli, Philippe Boutinaud

\section{- To cite this version:}

Enrico Cavalli, Gianluca Calestani, Francesco Mezzadri, Raffaele Faoro, Mauro Tonelli, et al.. Structural effects on the emission properties of Pr3+-doped Ba2NaNb5O15 crystals. Journal of Physics D: Applied Physics, 2010, 43 (45), pp.455404. 10.1088/0022-3727/43/45/455404 . hal-00569742

\section{HAL Id: hal-00569742 \\ https://hal.science/hal-00569742}

Submitted on 25 Feb 2011

HAL is a multi-disciplinary open access archive for the deposit and dissemination of scientific research documents, whether they are published or not. The documents may come from teaching and research institutions in France or abroad, or from public or private research centers.
L'archive ouverte pluridisciplinaire HAL, est destinée au dépôt et à la diffusion de documents scientifiques de niveau recherche, publiés ou non, émanant des établissements d'enseignement et de recherche français ou étrangers, des laboratoires publics ou privés. 


\title{
Structural effects on the emission properties of $\mathrm{Pr}^{3+}$-doped $\mathrm{Ba}_{2} \mathrm{NaNb}_{5} \mathrm{O}_{15}$ crystals
}

\author{
Enrico Cavalli ${ }^{1, *}$, Gianluca Calestani ${ }^{1}$, Francesco Mezzadri ${ }^{1}$, Raffaele Faoro ${ }^{2}$, Mauro \\ Tonelli $^{2}$ and Philippe Boutinaud ${ }^{3}$ \\ ${ }^{1}$ Dipartimento di Chimica Generale ed Inorganica, Chimica Analitica, Chimica Fisica, \\ Università di Parma, Parma, Italy. \\ 2 NEST-Istituto di Nanoscienze-CNR, Dipartimento di Fisica, Università di Pisa, Pisa, \\ Italy. \\ ${ }^{3}$ Clermont Université, ENSCCF, Laboratoire des Matériaux Inorganiques, BP10448, F- \\ 63000 Clermont-Ferrand, France. \\ * Corresponding author. E-mail address: enrico.cavalli@unipr.it
}

\begin{abstract}
Single crystals of $\mathrm{Ba}_{2} \mathrm{NaNb}_{5} \mathrm{O}_{15}$ doped with $\mathrm{Pr}^{3+}$ have been grown from sodium tetraborate flux. Their emission properties have been measured as a function of the doping level under different excitation and temperature conditions. The experimental observations have been accounted for by considering the effects of the crystal structure, of the doping mechanisms and of the interactions between host lattice and doping ions. The proposed conclusions have been verified by means of single crystal X-ray diffraction measurements and the resulting site occupancies of the active ions have been discussed in the light of the synthesis procedure.
\end{abstract}

PACS: 78.55.Hx; 61.66.Fn

\section{Introduction}

$\mathrm{Ba}_{2} \mathrm{NaNb}_{5} \mathrm{O}_{15}$ (BNN) belongs to the family of the niobates with the tungsten bronze (TB) structure. These compounds have attractive photorefractive, ferroelectric and non linear optical properties [1]. BNN is also an interesting host material for luminescent ions. $\mathrm{Nd}^{3+}$-doped crystals have been investigated in order to develop self doubling laser media [2, 3]. Studies extended to $\mathrm{BNN}$ activated with $\mathrm{Yb}^{3+}$ [4], $\mathrm{Er}^{3+}[5], \mathrm{Tm}^{3+}$ and $\mathrm{Ho}^{3+}$ $[6,7]$ have confirmed its potentialities as host lattice for laser ions. We have recently explored the visible emission properties of $\mathrm{BNN}$ crystals activated with $\mathrm{Eu}^{3+}, \mathrm{Dy}^{3+}, \mathrm{Tb}^{3+}$ and $\mathrm{Sm}^{3+}$ [8], pointing out the issues concerning the site occupancy in this host lattice and the analogies with $\mathrm{SBN}: \mathrm{Ln}^{3+}\left(\operatorname{Ln}^{3+}=\right.$ rare earth ions). In this paper we thoroughly investigate the emission properties of $\mathrm{Pr}^{3+}$-doped BNN (hereafter Pr:BNN) crystals as a function of the temperature, of the doping concentration and of the excitation conditions. Our interest in this system is related to different interconnected aspects: the development of a new visible emitting material, the analysis of its excited states dynamics and of the interactions between optical centres and lattice constituents in the light of the structural properties of the host and of the $\operatorname{Pr}^{3+}$ site occupancy, the possibility of extending the obtained information to other members of the TB niobate family, and so on.

\section{Experimental}

2.1 Crystal growth.

Single crystals of BNN singly doped with $\mathrm{Pr}^{3+}$ were grown by means of the flux growth method. Pure $\mathrm{BaO}$, $\mathrm{Nb}_{2} \mathrm{O}_{5}$ and $\mathrm{Na}_{2} \mathrm{~B}_{4} \mathrm{O}_{7}$ were used as starting materials. The doping ions were added as $\operatorname{Pr}_{6} \mathrm{O}_{11}$ with nominal $0.5 \%, 2 \%$ and $8 \%$ molar ratios with respect to $\mathrm{Ba}$. The starting mixture was placed in a Pt crucible and heated to melt $\left(1250{ }^{\circ} \mathrm{C}\right)$ in a horizontal furnace. After a $12 \mathrm{~h}$ soaking time, the temperature was slowly lowered $\left(2-3{ }^{\circ} \mathrm{C} / \mathrm{h}\right)$ to $400{ }^{\circ} \mathrm{C}$, then the furnace was turned off. Crystals with size up to of $2 \times 2 \times 3 \mathrm{~mm}^{3}$ and of sufficient optical quality were separated from the flux by dissolving it in hot diluted $\mathrm{HCl}$. The structural properties of the grown crystals will be discussed in details in Sect. 4. For the moment it is sufficient to point out that the incorporation of $\mathrm{Pr}^{3+}$ ions into the $\mathrm{BNN}$ lattice requires charge compensation that, combined with 
the intrinsic disorder of the TTB structure, results in the formation of different non equivalent optical centers and then in a significant inhomogeneous broadening of the absorption and emission features.

\subsection{Characterization.}

Single crystal X-ray diffraction (XRD) data were collected on a modified Philips PW1100 single crystal diffractometer using graphite monochromatized Mo K $\alpha$ radiation. Experimental details are reported in Table 1.

The room temperature emission and excitation spectra were measured using a Fluoromax-3 (Jobin-Yvon) spectrofluorimeter. The low temperature spectra were measured in the 485-760 nm range by using an Argon laser in single-line configuration to pump the ${ }^{3} \mathrm{P}_{0}$ manifold. The crystal was mounted on the cold finger of a closed-cycle He cryocooler. The luminescence was chopped and focused by a $75 \mathrm{~mm}$ focal lens on the input slit of a D330 Hillger \& Watts monochromator with $300 \mathrm{~mm}$ focal length (resolution: $0.1 \mathrm{~nm}$ ), processed by a lock-in amplifier and revealed by means of a S20 photomultiplier. A Glan-Thomson prism was placed at the entrance slit of the monochromator in order to perform polarized measurements. The decay time measurements were carried out upon $445 \mathrm{~nm}$ excitation by means of the second harmonic of tunable Ti-Sa pulsed laser (pulse duration $\sim 30 \mathrm{~ns}$, repetition rate $10 \mathrm{~Hz}$ ).

\section{Luminescence spectroscopy}

\section{1. $10 \mathrm{~K}$ emission spectra.}

The $10 \mathrm{~K}$ polarized emission spectra of $0.5 \%, 2 \%$ and $8 \%$ Pr:BNN measured upon $476.5 \mathrm{~nm} \mathrm{CW}$ laser excitation are shown in figure 1 . They are composed of four emission manifolds: the intense ${ }^{3} \mathrm{P}_{0} \rightarrow{ }^{3} \mathrm{H}_{4}$ transition at $495 \mathrm{~nm}$, the weak ${ }^{3} \mathrm{P}_{0} \rightarrow{ }^{3} \mathrm{H}_{5}$ multiplet at around $550 \mathrm{~nm}$, a complex band system in the $600-670$ nm range, including the ${ }^{1} \mathrm{D}_{2} \rightarrow{ }^{3} \mathrm{H}_{4}(\sim 605 \mathrm{~nm}),{ }^{3} \mathrm{P}_{0} \rightarrow{ }^{3} \mathrm{H}_{6}(610-650 \mathrm{~nm})$ and ${ }^{3} \mathrm{P}_{0} \rightarrow{ }^{3} \mathrm{~F}_{2}(650-670 \mathrm{~nm})$ transitions, and the weak ${ }^{3} \mathrm{P}_{0} \rightarrow{ }^{3} \mathrm{~F}_{3,4}$ emission at around $750 \mathrm{~nm}$.

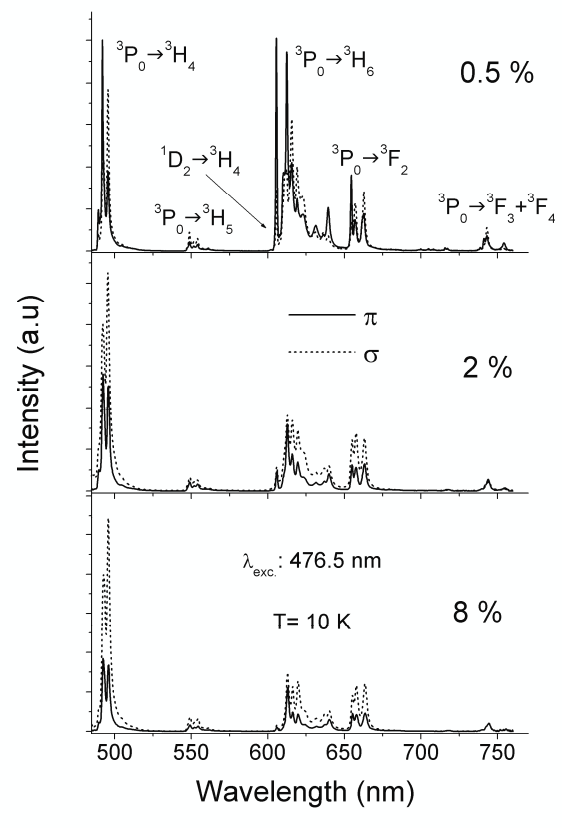

Figure 1. Polarized emission spectra measured upon $476.5 \mathrm{~nm}$ laser excitation.

The intensity ratio between the observed manifolds as well as the polarization behaviour of their components change with the doping level. This in our opinion is the consequence of the presence of different (and interacting) optical centres whose relative concentrations vary with the total $\operatorname{Pr}^{3+}$ content independently one from the other. As expected, all features are inhomogeneously broadened, the sharpest ones having FWHM (full width at half maximum) values of the order of $30-40 \mathrm{~cm}^{-1}$. The broadness of the emission features 
depend on the excitation wavelength: as an example, Figure 2 (a) compares the 600-670 nm manifold measured upon 476.5 and $458 \mathrm{~nm}$ laser excitation. The latter is significantly broader, indicating that the 458 $\mathrm{nm}$ radiation excites a number of non-equivalent centres larger than that excited by the $476.5 \mathrm{~nm}$ one. It is clear from in figure 2 (b) that that the relative intensity of the ${ }^{1} \mathrm{D}_{2} \rightarrow{ }^{3} \mathrm{H}_{4}$ emission transition strongly decreases with the doping level. This is an expected result, since the emission properties of $\operatorname{Pr}^{3+}$-doped compounds are significantly affected by the activator concentration. In the case of the ${ }^{3} \mathrm{P}_{0}$ level the concentration quenching is ascribed to cross relaxation processes of the type [9]:

$$
\begin{aligned}
& {\left[{ }^{3} \mathrm{P}_{0},{ }^{3} \mathrm{H}_{4}\right] \rightarrow\left[{ }^{1} \mathrm{G}_{4},{ }^{1} \mathrm{G}_{4}\right]} \\
& {\left[{ }^{3} \mathrm{P}_{0},{ }^{3} \mathrm{H}_{4}\right] \rightarrow\left[{ }^{1} \mathrm{D}_{2},{ }^{3} \mathrm{H}_{6}\right]}
\end{aligned}
$$

shown in Fig. 3(a).
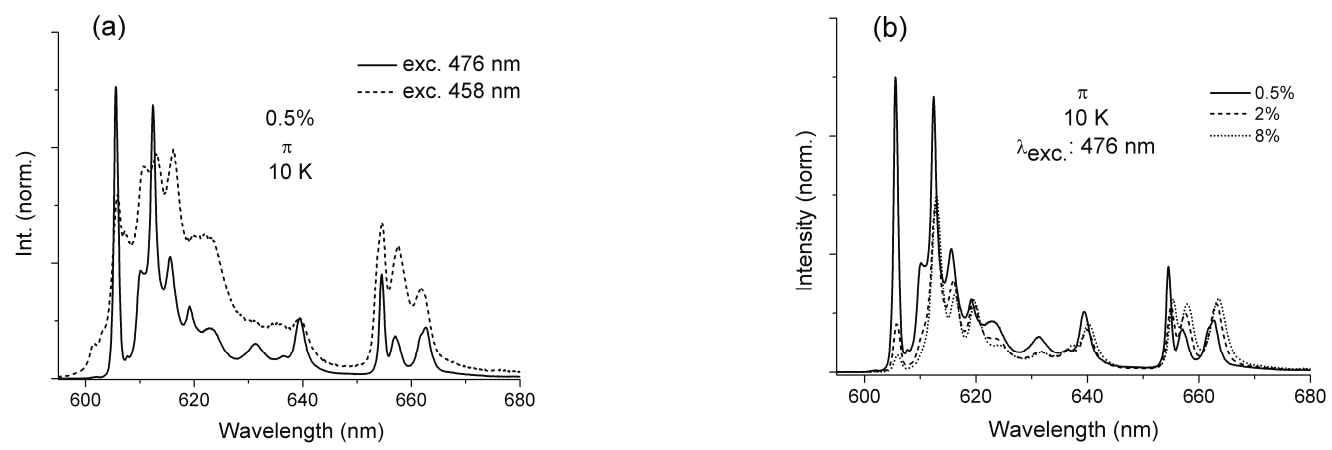

Figure 2. The $600-680 \mathrm{~nm}$ emission manifold ( $\pi$ polarization) measured for different excitation wavelengths (a) and $\operatorname{Pr}^{3+}$ concentrations (b).

Process (i) is not resonant, since the two involved transitions occur at energies differing by about $950 \mathrm{~cm}^{-1}$, and process (ii) is nearly but not fully resonant. In consequence, both are expected to be favoured by phonon assistance, since phonons of suitable energy are available in the IR or Raman spectrum [10]. This mechanism is concomitant with the ${ }^{3} \mathrm{P}_{0} \rightarrow{ }^{1} \mathrm{D}_{2}$ multiphonon relaxation. The cross relaxation involving the ${ }^{1} \mathrm{D}_{2}$ state (figure $3(b))$ :

$$
\left[{ }^{1} \mathrm{D}_{2},{ }^{3} \mathrm{H}_{4}\right] \rightarrow\left[{ }^{1} \mathrm{G}_{4},{ }^{3} \mathrm{~F}_{4}\right]
$$

is in practice a resonant process, then we have to expect a strong concentration and a weak temperature dependence. In addition to these processes, the mechanism involving charge transfer states have to be considered.

\subsection{K emission spectra.}

As the temperature increases the emission bands broaden and their intensity decreases. At $300 \mathrm{~K}$ the spectra present a broad luminescence in the 600-660 nm range, with two components: the more intense (composed by the ${ }^{1} \mathrm{D}_{2} \rightarrow{ }^{3} \mathrm{H}_{4}$ and ${ }^{3} \mathrm{P}_{0} \rightarrow{ }^{3} \mathrm{H}_{6}$ transitions) has maximum at $605 \mathrm{~nm}$ that shifts to $620 \mathrm{~nm}$ as with concentration increasing as a consequence of the quenching of the ${ }^{1} \mathrm{D}_{2}$ emission, the minor one $\left({ }^{3} \mathrm{P}_{0} \rightarrow{ }^{3} \mathrm{~F}_{2}\right)$ peaks at $655 \mathrm{~nm}$ (Fig. 4 (a)). The relative intensities of the spectral components depend on the excitation wavelength: this is a typical consequence of the presence of the IVCT state that favours the population of the ${ }^{1} \mathrm{D}_{2}$ state. The spectrum of the diluted crystal is rather similar to that reported for SBN:Pr (1\%) [11], indicating similar environments for the optically active ions in the two lattices. The excitation spectrum (Fig. 4 (b)) is characterized by three band systems located in the 420-500, 340-410 and <300 nm regions. The last one corresponds to the host absorption band feeding the $\operatorname{Pr}^{3+}$ emission through an energy transfer process. The manifold in the blue region, resolved into three well separated components, is ascribed to the ${ }^{3} \mathrm{H}_{4} \rightarrow{ }^{3} \mathrm{P}_{\mathrm{J}}$ $(\mathrm{J}=0,1,2),{ }^{1} \mathrm{I}_{6}$ absorption of $\mathrm{Pr}^{3+}$. The band located in the $340-410 \mathrm{~nm}$ range is to low in energy to be assigned to a $4 \mathrm{f}^{2} \rightarrow 4 \mathrm{f}^{1} 5 \mathrm{~d}^{1}$ transition and it is ascribed to the intervalence charge transfer (IVCT) process: 


$$
\mathrm{Pr}^{3+}+\mathrm{Nb}^{5+} \rightarrow \mathrm{Pr}^{4+}+\mathrm{Nb}^{4+}
$$

already observed in $\operatorname{Pr}^{3+}$-doped niobates [12]. It is interesting to note that the IVCT maximum shifts to higher energy as the doping level increases: it is located at $374 \mathrm{~nm}$ in the $0.5 \%$ case, at $368 \mathrm{~nm}$ in the $2 \%$ and at 345 $\mathrm{nm}$ in the $8 \%$ case. As pointed out by Boutinaud et al. [12], the position of the IVCT state is related to the optical electronegativity of the involved transition metal ion $\left(\mathrm{Nb}^{5+}\right.$ in the present case) and to its minimum distance with respect to the lanthanide ion.
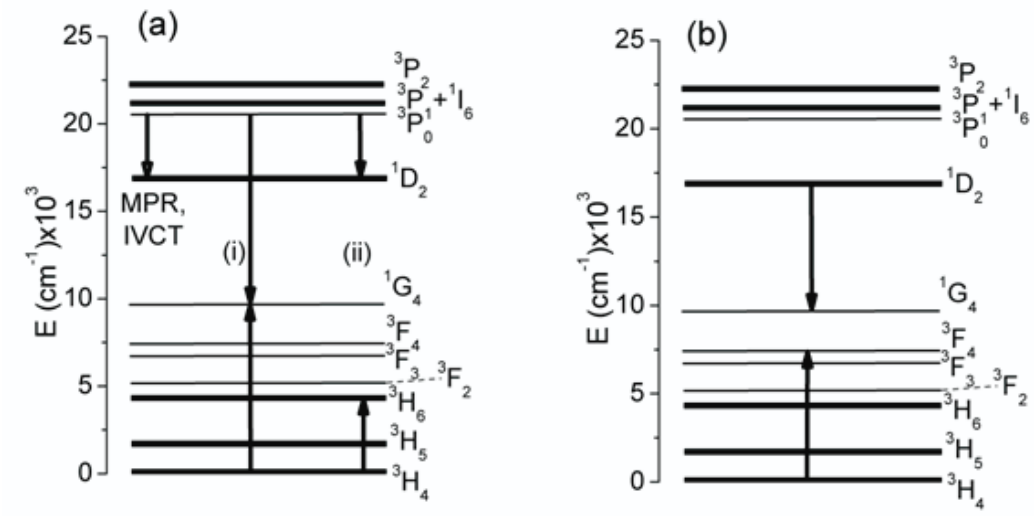

Figure 3. Non radiative mechanisms affecting the ${ }^{3} \mathrm{P}_{0}$ (a) and ${ }^{1} \mathrm{D}_{2}$ (b) emission of $\operatorname{Pr}^{3+}$ in oxide lattices.

This dependence is formalized by the empirical equation:

$$
\operatorname{IVCT}\left(\operatorname{Pr}^{3+}, \mathrm{cm}^{-1}\right)=58800-49800 \frac{\chi_{\text {opt }}\left(M^{n+}\right)}{d\left(\operatorname{Pr}^{3+}-M^{n+}\right)}
$$

where $\chi_{\text {opt }}\left(M^{n+}\right)$ is the optical electronegativity of the closed-shell transition metal ion $\mathrm{M}^{\mathrm{n}+}$ and $d\left(\operatorname{Pr}^{3+}\right.$ $\left.\mathrm{M}^{\mathrm{n}+}\right)$ is the shortest interatomic distance between $\operatorname{Pr}^{3+}$ and $\mathrm{M}^{\mathrm{n}+}$. In the diluted crystals the shortest $\mathrm{Pr}^{3+}-\mathrm{Nb}^{5+}$ distance calculated using eq. (1) is $2.89 \AA$. In the BNN lattice however, $\operatorname{Pr}^{3+}$ is expected to replace $\mathrm{Na}^{+}\left(\mathrm{A}_{2}\right.$ site) or $\mathrm{Ba}^{2+}\left(\mathrm{A}_{1}\right.$ site). In both cases the shortest $\mathrm{Pr}^{3+}-\mathrm{Nb}^{5+}$ distances, 3.36 and $3.60 \AA$ respectively, are not consistent with the calculated value. Only in the case of $\mathrm{C}$ site occupancy the resulting distance, $2.90 \AA$, is practically coincident with the evaluated one.

(a)

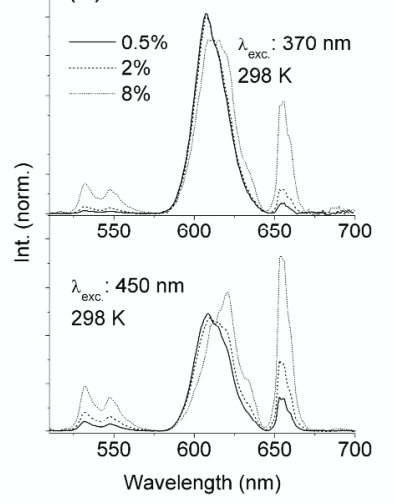

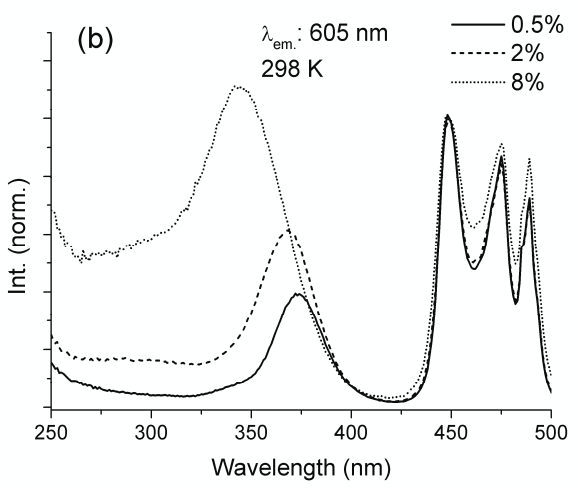

Fig. 4. Room temperature unpolarized emission (a) and excitation (b) spectra of Pr:BNN. 
In addition, the IVCT shift with increasing $\operatorname{Pr}^{3+}$ concentration indicates that the average shortest $\mathrm{Pr}^{3+}-\mathrm{Nb}^{5+}$ distance increases with the doping level. These are unexpected and interesting issues that we have decided to investigate in more details by XRD techniques.

Table 1. Crystal data and refinement parameters

\begin{tabular}{|c|c|c|c|}
\hline Compound & Pr:BNN (0.5\%) & Pr:BNN (2\%) & Pr:BNN (8\%) \\
\hline Formula weight & 998.92 & 999.12 & 998.67 \\
\hline Crystal habit & needle & needle & needle \\
\hline Crystal colour & colorless & colorless & colorless \\
\hline Crystal dimensions, $\mathrm{mm}$ & $0.53 \times 0.07 \times 0.05$ & $0.41 \times 0.07 \times 0.07$ & $0.50 \times 0.08 \times 0.08$ \\
\hline Crystallographic system & tetragonal & tetragonal & tetragonal \\
\hline Space group & $\mathrm{P} 4 \mathrm{bm}$ & $\mathrm{P} 4 \mathrm{bm}$ & $\mathrm{P} 4 \mathrm{bm}$ \\
\hline \multicolumn{4}{|l|}{ Cell parameters: } \\
\hline $\mathrm{a}, \AA$ & $12.465(5)$ & $12.464(4)$ & $12.463(4)$ \\
\hline c, $\AA$ & $3.986(2)$ & $3.986(2)$ & $3.984(2)$ \\
\hline$\alpha$ & 90 & 90 & 90 \\
\hline$\beta$, & 90 & 90 & 90 \\
\hline$\gamma, \circ$ & 90 & 90 & 90 \\
\hline $\mathrm{V}, \AA^{3}$ & $619.3(5)$ & $619.2(4)$ & $618.8(4)$ \\
\hline $\mathrm{Z}$ & 2 & 2 & 2 \\
\hline $\mathrm{D}_{\text {calc }}, \mathrm{Mg} \mathrm{m}^{-3}$ & 5.357 & 5.359 & 5.360 \\
\hline Linear abs. coefficient, $\mathrm{cm}^{-1}$ & 10.784 & 10.818 & 10.865 \\
\hline Absorpt. correction type & $\psi$-scan & $\psi$-scan & $\psi$-scan \\
\hline Absorpt. correction $\mathrm{T}_{\max }$ & 0.411 & 0.468 & 0.421 \\
\hline Absorpt. correction $\mathrm{T}_{\min }$ & 0.576 & 0.404 & 0.351 \\
\hline Temperature, $\mathrm{K}$ & 293 & 293 & 293 \\
\hline Radiation, $\AA$ & 0.71073 & 0.71073 & 0.71073 \\
\hline $2 \theta$ range, ${ }^{\circ}$ & $3.27-35.01$ & $3.27-35.01$ & $3.27-45.02$ \\
\hline Total measured reflections & 2974 & 2976 & 5473 \\
\hline Unique reflections & 802 & 804 & 1451 \\
\hline Unique observed reflection & 792 & 740 & 1212 \\
\hline Criterion for obs. reflections & $\mathrm{I}>2 \sigma(\mathrm{I})$ & $\mathrm{I}>2 \sigma(\mathrm{I})$ & $\mathrm{I}>2 \sigma(\mathrm{I})$ \\
\hline Reflections used (NO) $^{\text {a }}$ & 802 & 804 & 1451 \\
\hline Refined parameters (NV) & 64 & 66 & 66 \\
\hline $\mathrm{NO} / \mathrm{NV}$ ratio & 12.53 & 12.18 & 21.98 \\
\hline $\mathrm{R}=\Sigma|\Delta \mathrm{F}| / \Sigma\left|\mathrm{F}_{\mathrm{o}}\right|^{\mathrm{b}}$ & 0.0274 & 0.0238 & 0.0439 \\
\hline $\mathrm{wR} 2=\left[\Sigma \mathrm{w}\left|\Delta \mathrm{F}^{2}\right|^{2} /\right.$ & 0.0664 & 0.0575 & 0.0999 \\
\hline \multicolumn{4}{|l|}{$\left.\sum \mathrm{W}\left|\mathrm{Fo}^{2}\right|^{2}\right]^{1 / 2 \mathrm{c}}$} \\
\hline $\mathrm{GOF}=\left[\Sigma \mathrm{w}\left|\Delta \mathrm{F}^{2}\right|^{2} /(\mathrm{NO}-\right.$ & 0.998 & 1.132 & 1.007 \\
\hline \multicolumn{4}{|l|}{$\mathrm{NV})]^{1 / 2}$} \\
\hline Flack parameter & $0.08(6)$ & $0.09(6)$ & $0.04(6)$ \\
\hline Extinction coefficient & $0.0154(9)$ & $0.0092(5)$ & $0.0091(10)$ \\
\hline Maximum shift/esd, last cycle & 0.002 & 0.001 & 0.04 \\
\hline Maximum residual peak, e/ $\AA^{3}$ & 1.50 & 1.98 & 2.06 \\
\hline
\end{tabular}

${ }^{\mathrm{a}}$ Refinement based on the reflections with $I>0$.

${ }^{\mathrm{b}}$ Calculated on the observed reflections.

${ }^{\mathrm{c}}$ Calculated on the reflections used in the refinement. 


\subsection{Decay time measurements}

The emission kinetics of both ${ }^{3} \mathrm{P}_{0}(655 \mathrm{~nm})$ and ${ }^{1} \mathrm{D}_{2}(605 \mathrm{~nm})$ states have been measured at different temperatures upon $455 \mathrm{~nm}$ excitation (Fig. 5). The profile of the ${ }^{3} \mathrm{P}_{0}$ emission is a single exponential only in the case of the diluted sample at $10 \mathrm{~K}$. As the temperature and/or the concentration increases the curves significantly deviates from the exponential behaviour. Possible reasons of this effect can be:

I. as the concentration increases the distribution of the $\mathrm{Pr}^{3+}$ ions among the different sites tend to vary, as well as the effect of the related charge compensation mechanisms.

II. the ${ }^{3} \mathrm{P}_{0} \rightarrow{ }^{1} \mathrm{D}_{2}$ multiphonon relaxation process requires at least four high energy $\left(840 \mathrm{~cm}^{-1}\right)$ host phonons to occur, since the gap between the involved levels is of the order of $3300-3500 \mathrm{~cm}^{-1}$. It then constitutes a temperature dependent contribution to the ${ }^{3} \mathrm{P}_{0}$ depopulation.

III. the temperature dependent cross relaxation mechanisms.

IV. the de-excitation through the IVCT state can be favoured by suitable phonon assistance and then could have some temperature dependence.

It is clearly impossible to analyze the profiles on the basis of a single reliable model. We have then evaluated the effective emission decay times using the eq (2) [13]:

$$
\tau=\frac{\int t \cdot I(t) d t}{\int I(t) d t}
$$

where $I(t)$ represents the luminescence intensity at time $t$. The obtained values, reported in Fig. 5 in proximity of the corresponding curves, evidence a relatively small variability, despite the number of processes potentially involved.

The $10 \mathrm{~K}^{1} \mathrm{D}_{2}$ profiles are characterized by a risetime, approximately of the order of $1 \mu \mathrm{s}$, confirming the feeding from the ${ }^{3} \mathrm{P}_{0}$ upper level through the II-IV processes above mentioned. At $298 \mathrm{~K}$ the risetime disappears because the above mentioned temperature dependent relaxation processes from ${ }^{3} \mathrm{P}_{0}$ become much more effective and the feeding process faster. The decays are non exponential in consequence of the presence of non equivalent optical centres. The values of the effective decay times, calculated with eq. (2), reveal a strong concentration dependence compatible with the resonant character of the $\left[{ }^{1} \mathrm{D}_{2},{ }^{3} \mathrm{H}_{4}\right] \rightarrow\left[{ }^{1} \mathrm{G}_{4},{ }^{3} \mathrm{~F}_{4}\right]$ cross relaxation responsible of the non radiative depopulation of the ${ }^{1} \mathrm{D}_{2}$ level.

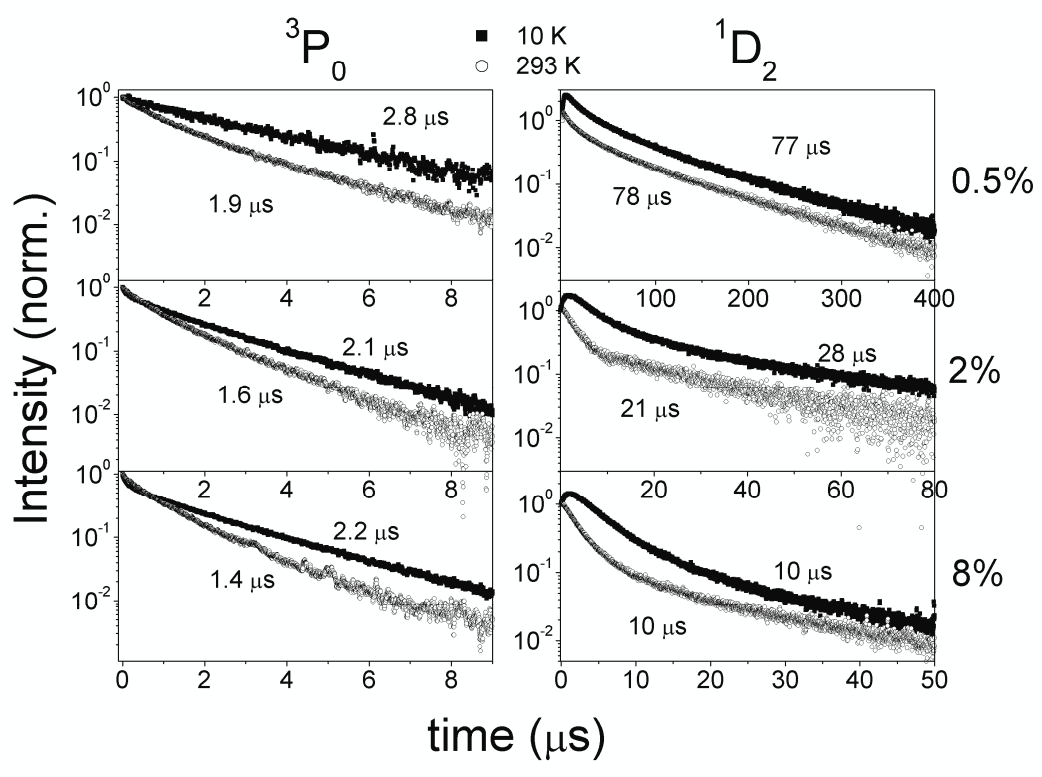

Fig. 5. Emission decay profiles of Pr:BNN. 


\section{Structural characterization}

Three single crystals with nominal $\mathrm{Pr} / \mathrm{Ba}$ ratios $0.5 \%, 2 \%$ and $8 \%$ were characterized by single crystal XRD. Crystal data are very similar, as reported in Table 1 , and consistent with the typical tetragonal tungsten bronze (TTB) structure, characterized by the structural formula $\left(\mathrm{A}_{1}\right)_{x}\left(\mathrm{~A}_{2}\right)_{y} \mathrm{C}_{z} \mathrm{~B}_{10} \mathrm{X}_{30}$, where $x$ can ideally vary in the 0-2 range and $y, z$ in the 0-4 range. The typical framework (Fig. 6) can be thought as derived from the perovskite structure by rotation of some $\left[\mathrm{BX}_{6}\right]$ polyhedra and is formed by corner sharing $\left[\mathrm{BX}_{6}\right]$ octahedral units whose linking produces three different types of channels (also called tunnels) containing the extraframework cations in $\mathrm{A}_{1}, \mathrm{~A}_{2}$, and $\mathrm{C}$ sites, respectively. In terms of coordination polyhedra, the $\mathrm{A}_{2}$ cations are 15-fold coordinated in the tunnel with a pentagonal section, the $\mathrm{A}_{1}$ cations are 12-fold coordinated in the surviving perovskite cage, and the $\mathrm{C}$ cations are 9-fold coordinated in channels characterized by a triangular section. In our case the structure was solved with SIR2002 [14] and refined with SHELX97 [15].

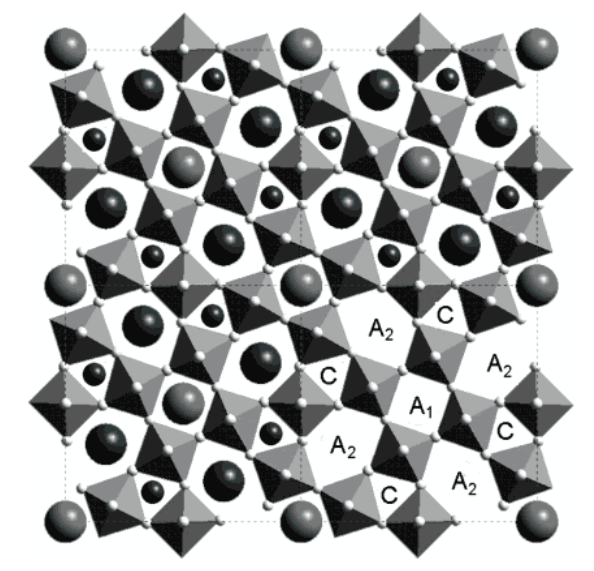

Figure 6. TTB structure with the conventional sites nomenclature.

After a preliminary structure refinement in which only the presence of $\mathrm{Ba}^{2+}$ and $\mathrm{Na}^{+}$(located in $\mathrm{A}_{2}$ and $\mathrm{A}_{1}$, respectively) as extra-framework cations was taken into account, difference Fourier maps revealed in all cases a residual electron density in the triangular channels, suggesting a partial cationic occupation of the corresponding C sites. Since these residuals were not detected in undoped BNN crystals previously characterized, a possible site occupation by praseodymium was considered. Owing to the reduced cage dimension, this hypothesis could appear quite rash, unless to evaluate carefully the local effects produced by structural modulation. In fact TTB structures, known for a great number of oxides and fluorides, are usually characterized in the low temperature region of the phase diagram (very often extending well above RT) by a typical structural modulation along the [110] crystallographic direction, ranging from incommensurate to commensurate depending on chemical composition and connected to the doubling of the $c$ parameter $(\approx 8 \AA)$. The structural modulation, ascribed to the existence of a cooperative tilt of the $\left[\mathrm{NbO}_{6}\right]$ octahedra that reduces the real symmetry from tetragonal to orthorhombic, is at the basis of ferroelasticity in these systems.

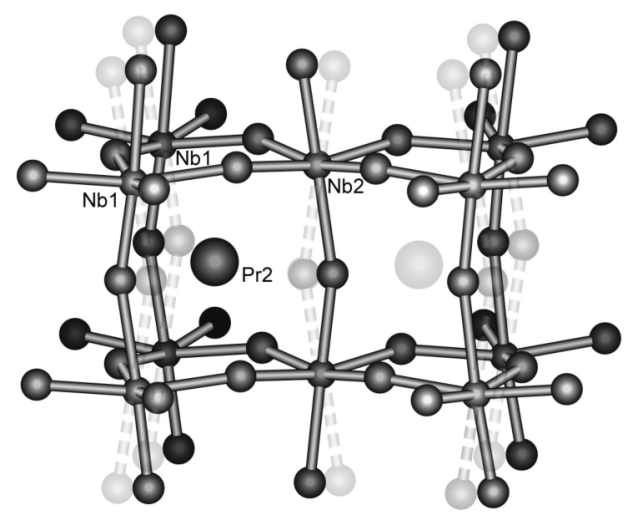

Fig. 7. Configurations of the triangular channels resulting from the modulation of the BNN structure and allowing the accommodation of the $\operatorname{Pr}^{3+}$ ions in the $\mathrm{C}$ site. 
The fundamental averaged structure of BNN at room temperature was determined at the end of the 1960s by Jamieson et al.[16].

Table 2. Atomic coordinates and displacement parameters $\left(\AA^{2}\right)$.

$\operatorname{Pr}: \operatorname{BNN}(0.5 \%)$

\begin{tabular}{ccccccc}
\hline atom & $\begin{array}{c}\text { site } \\
\text { multiplicity }\end{array}$ & $\mathrm{x}$ & $\mathrm{y}$ & $\mathrm{z}$ & $\mathrm{U}_{\mathrm{eq}}$ & $\begin{array}{c}\text { site } \\
\text { occupancy }\end{array}$ \\
\hline $\mathrm{Nb} 2$ & 2 & 0.0000 & 0.5000 & 0.5000 & $0.00457(17)$ & 1 \\
$\mathrm{Nb} 1$ & 8 & $0.07404(3)$ & $0.20942(3)$ & $0.4994(6)$ & $0.00176(13)$ & 1 \\
$\mathrm{Ba} 2$ & 8 & $0.3357(3)$ & $0.1787(3)$ & $0.0132(6)$ & $0.0115(7)$ & $0.4845(13)$ \\
$\mathrm{Na} 1$ & 2 & 0.0000 & 0.0000 & $0.007(3)$ & $0.0074(7)$ & 1 \\
$\mathrm{Pr} 2$ & 4 & $0.1128(15)$ & $0.3872(15)$ & $0.051(7)$ & 0.010 & $0.0183(16)$ \\
$\mathrm{O} 1$ & 8 & $-0.0064(3)$ & $0.3437(3)$ & $0.546(3)$ & $0.0173(14)$ & 1 \\
$\mathrm{O} 2$ & 4 & $0.2160(3)$ & $0.2840(3)$ & $0.536(3)$ & $0.0081(13)$ & 1 \\
$\mathrm{O} 3$ & 8 & $0.1410(4)$ & $0.0698(3)$ & $0.558(2)$ & $0.0193(15)$ & 1 \\
$\mathrm{O} 41$ & 8 & $0.0914(10)$ & $0.1952(9)$ & $0.033(5)$ & $0.0230(19)$ & 0.50 \\
$\mathrm{O} 42$ & 8 & $0.0572(10)$ & $0.2150(10)$ & $0.044(4)$ & $0.0230(19)$ & 0.50 \\
$\mathrm{O} 5$ & 4 & $0.0141(7)$ & $0.4859(7)$ & $0.018(8)$ & $0.020(3)$ & 0.50 \\
\hline
\end{tabular}

Pr:BNN (2\%)

\begin{tabular}{ccccccc}
\hline \multirow{2}{*}{ atom } & $\begin{array}{c}\text { site } \\
\text { multiplicity }\end{array}$ & $\mathrm{x}$ & $\mathrm{y}$ & $\mathrm{z}$ & $\mathrm{U}_{\text {eq }}$ & $\begin{array}{c}\text { site } \\
\text { occupancy }\end{array}$ \\
\hline $\mathrm{Nb} 2$ & 2 & 0.0000 & 0.5000 & 0.5000 & $0.00531(15)$ & 1 \\
$\mathrm{Nb} 1$ & 8 & $0.07410(3)$ & $0.20939(3)$ & $0.4971(6)$ & $0.00217(11)$ & 1 \\
$\mathrm{~B} 2$ & 8 & $0.3365(2)$ & $0.1793(2)$ & $0.0103(7)$ & $0.0105(5)$ & $0.4809(12)$ \\
$\mathrm{Na} 1$ & 2 & 0.0000 & 0.0000 & $0.001(3)$ & $0.0175(12)$ & $0.970(4)$ \\
$\mathrm{Pr} 1$ & 2 & 0.0000 & 0.0000 & $0.001(3)$ & $0.0175(12)$ & $0.031(4)$ \\
$\mathrm{Pr} 2$ & 4 & $0.1162(19)$ & $0.3838(19)$ & $0.054(9)$ & 0.010 & $0.0131(14)$ \\
$\mathrm{O} 1$ & 8 & $-0.0063(3)$ & $0.3438(3)$ & $0.544(3)$ & $0.0172(13)$ & 1 \\
$\mathrm{O} 2$ & 4 & $0.2163(3)$ & $0.2837(3)$ & $0.536(3)$ & $0.0073(13)$ & 1 \\
$\mathrm{O} 3$ & 8 & $0.1414(3)$ & $0.0698(3)$ & $0.555(2)$ & $0.0192(15)$ & 1 \\
$\mathrm{O} 41$ & 8 & $0.0904(9)$ & $0.1959(9)$ & $0.025(6)$ & $0.0258(19)$ & 0.50 \\
$\mathrm{O} 42$ & 8 & $0.0584(9)$ & $0.2153(9)$ & $0.033(5)$ & $0.0258(19)$ & 0.50 \\
$\mathrm{O} 5$ & 4 & $0.0144(6)$ & $0.4856(6)$ & $0.023(6)$ & $0.016(3)$ & 0.50 \\
\hline
\end{tabular}

Pr:BNN (8\%)

\begin{tabular}{ccccccc}
\hline atom & $\begin{array}{c}\text { site } \\
\text { multiplicity }\end{array}$ & $\mathrm{x}$ & $\mathrm{y}$ & $\mathrm{z}$ & $\mathrm{U}_{\text {eq }}$ & $\begin{array}{c}\text { site } \\
\text { occupancy }\end{array}$ \\
\hline $\mathrm{Nb} 2$ & 2 & 0.0000 & 0.5000 & 0.5000 & $0.00611(12)$ & 1 \\
$\mathrm{Nb} 1$ & 8 & $0.07395(2)$ & $0.20972(2)$ & $0.5031(5)$ & $0.00527(8)$ & 1 \\
$\mathrm{Ba} 2$ & 8 & $0.33566(16)$ & $0.17868(17)$ & $0.0146(5)$ & $0.0139(4)$ & $0.4720(10)$ \\
$\mathrm{Na} 1$ & 2 & 0.0000 & 0.0000 & $0.007(2)$ & $0.0138(7)$ & $0.920(4)$ \\
$\mathrm{Pr} 1$ & 2 & 0.0000 & 0.0000 & $0.007(2)$ & $0.0138(7)$ & $0.080(3)$ \\
$\mathrm{Pr} 2$ & 4 & $0.112(2)$ & $0.388(2)$ & $-0.025(15)$ & 0.010 & $0.0084(13)$ \\
$\mathrm{O} 1$ & 8 & $-0.0065(3)$ & $0.3436(3)$ & $0.542(3)$ & $0.0275(18)$ & 1 \\
$\mathrm{O} 2$ & 4 & $0.2162(3)$ & $0.2838(3)$ & $0.540(4)$ & $0.017(2)$ & 1 \\
$\mathrm{O} 3$ & 8 & $0.1404(3)$ & $0.0691(3)$ & $0.554(4)$ & $0.036(3)$ & 1 \\
$\mathrm{O} 41$ & 8 & $0.0909(8)$ & $0.1962(8)$ & $0.037(5)$ & $0.0280(17)$ & 0.50 \\
$\mathrm{O} 42$ & 8 & $0.0568(8)$ & $0.2139(8)$ & $0.037(5)$ & $0.0280(17)$ & 0.50 \\
$\mathrm{O} 5$ & 4 & $0.0131(6)$ & $0.4869(6)$ & $0.044(5)$ & $0.020(3)$ & 0.50 \\
\hline
\end{tabular}


The first attempt to describe the modulated structure was made by Lin and Bursill [17] on the basis of electron diffraction (ED) data in an orthorhombic supercell with $a \approx b \approx 2 a_{T T B} \sqrt{2}, c=2 c_{T T B}$ and space group $\operatorname{Im} 2 a$. Further studies on de-twninned crystals by Labbe' et al. [18] demonstrated that the supercell describing the quasi-commensurate modulation is in reality half in volume, being $b \approx a_{T T B} \sqrt{2}$, and its symmetry is consistent with the Bbm2 space group.The results of Labbé were then confirmed by Fabbrici et al. [19] for $\mathrm{K}_{0.525} \mathrm{FeF}_{3}$ and by Mezzadri et al. [20] for $\mathrm{K}_{0.6} \mathrm{FeF}_{3}$, confirming this modulation as generally distinctive of TTB phases and not only of BNN. The use of de-twninned crystals revealed to be fundamental in structural studies of BNN, where ferroelastic domains connected to the exchange of the $a$ and $b$ axes of the superstructure occurs on a scale that is below the coherence length of X-ray, so that the modulation satellites are usually observed only by electron diffraction (ED). In spite of the typical absence of modulation satellites, the existence of the structural modulation leaves a characteristic trace in single crystal XRD data, consisting in an anomalous elongation of the anisotropic displacement parameters (a.d.p.'s) of the atoms, that is indicative of static disorder. The phenomenon is particularly significant for the apical $\mathrm{O}$ atoms of the $\left[\mathrm{NbO}_{6}\right]$ octahedra (the mostly affected by the cooperative tilt) and for the $\mathrm{Ba}$ atoms hosted in the large pentagonal channels (that moves in the ab plane in agreement with the displacements of the apical $\mathrm{O}$ atoms lying on the same plane). Once the structural modulation is taken into account (at least partially) by refining these atoms on disordered positions, the triangular channels become able to host $\mathrm{Pr}^{3+}$ ions (Fig. 7).

Table 3. Selected bond lengths and distances $(\AA)$. Bonds denoted by a and b superscripts represents possible alternatives produced by the disordered description of the modulation in the fundamental cell.

\begin{tabular}{|c|c|c|c|}
\hline & Pr:BNN (0.5\%) & Pr:BNN $(2 \%)$ & Pr:BNN (8\%) \\
\hline $\mathrm{Nb} 2-\mathrm{O} 5$ & $1.94(3)$ & $1.92(2)$ & $1.831(18)$ \\
\hline $\mathrm{Nb} 2-\mathrm{O} 1$ & $4 \times 1.958(4)$ & $4 \times 1.956(4)$ & $4 \times 1.958(4)$ \\
\hline $\mathrm{Nb} 2-\mathrm{O} 5$ & $2.08(3)$ & $2.10(2)$ & $2.179(18)$ \\
\hline $\mathrm{Nb} 1-\mathrm{O} 42^{\mathrm{a}}$ & $1.830(17)$ & $1.86(2)$ & $1.870(19)$ \\
\hline $\mathrm{Nb} 1-\mathrm{O} 41^{\mathrm{b}}$ & $1.88(2)$ & $1.90(2)$ & $1.88(2)$ \\
\hline Nb1- O3 & $1.944(4)$ & $1.945(4)$ & $1.949(4)$ \\
\hline Nb1- O1 & $1.960(4)$ & $1.961(4)$ & $1.953(3)$ \\
\hline Nb1- O3 & $2.000(4)$ & $1.997(4)$ & $1.991(4)$ \\
\hline Nb1- O2 & $2.004(2)$ & $2.006(2)$ & $2.005(2)$ \\
\hline $\mathrm{Nb} 1-\mathrm{O} 41^{\mathrm{a}}$ & $2.15(2)$ & $2.12(2)$ & $2.14(2)$ \\
\hline $\mathrm{Nb} 1-\mathrm{O} 42^{\mathrm{b}}$ & 2.181(18) & $2.15(2)$ & $2.138(19)$ \\
\hline Na1(Pr1)-O3 & $4 \times 2.655(10)$ & $4 \times 2.651(10)$ & $4 \times 2.657(12)$ \\
\hline $\mathrm{Na} 1(\mathrm{Pr} 1)-\mathrm{O} 41$ & $4 \times 2.688(11)$ & $4 \times 2.690(11)$ & $4 \times 2.698(10)$ \\
\hline $\mathrm{Na} 1(\mathrm{Pr} 1)-\mathrm{O} 42$ & $4 \times 2.777(12)$ & $4 \times 2.783(11)$ & $4 \times 2.761(10)$ \\
\hline Pr2-O5 & 2.24(3) & $2.31(4)$ & $2.22(4)$ \\
\hline $\operatorname{Pr} 2-041^{\mathrm{a}}$ & $2 \times 2.41(2)$ & $2 \times 2.37(2)$ & $2 \times 2.42(3)$ \\
\hline $\operatorname{Pr} 2-\mathrm{O} 42^{\mathrm{b}}$ & $2 \times 2.26(2)$ & $2 \times 2.22(2)$ & $2 \times 2.29(2)$ \\
\hline Pr2-O1 & $2 \times 2.53(2)$ & $2 \times 2.53(3)$ & $2 \times 2.34(5)$ \\
\hline Pr2-O1 & $2 \times 2.56(3)$ & $2 \times 2.59(3)$ & $2 \times 2.76(5)$ \\
\hline Pr2-O2 & $2.65(3)$ & $2.61(4)$ & $2.53(5)$ \\
\hline Pr2-O2 & $2.74(3)$ & $2.72(4)$ & $2.91(5)$ \\
\hline Pr2-Nb (av.) & $2.89(3)$ & $2.91(4)$ & $2.88(5)$ \\
\hline Pr1-Nb (av.) & $3.412(7)$ & $3.412(8)$ & $3.413(5)$ \\
\hline $\begin{array}{c}\text { Pr-Nb } \\
\text { weighted av. }\end{array}$ & $2.89(3)$ & $3.18(2)$ & $3.319(12)$ \\
\hline
\end{tabular}


Following this idea the occupancies of the extra-framework cations were refined in the final cycles, by constraining the total charge to compensate the anionic framework. The $\operatorname{Pr}^{3+}$ concentration of the most diluted crystal estimated by this approach significantly exceeds the nominal doping level and cannot be considered quantitatively reliable. Nevertheless these results allow concluding that in this sample praseodymium occupies the $\mathrm{C}$ site, compensating a small Ba deficiency in the $\mathrm{A}_{2}$ site. The presence of some $\mathrm{Pr}^{3+}$ in the $\mathrm{A}_{1}$ site of $\mathrm{BNN}: \operatorname{Pr}(0.5 \%)$ cannot be excluded. However, being the refined occupancy of the order of the standard deviation, the Na occupancy of $\mathrm{A}_{1}$ site was fixed to the unit in the last refinement cycles. The occupation of the $\mathrm{C}$ site by $\mathrm{Pr}$ is probably forced by the large $\mathrm{Na}$ excess in the flux that inhibits the competitor role of $\operatorname{Pr}$ for the $A_{1}$ site. As the doping level increases $\operatorname{Pr}^{3+}$ starts to occupy preferentially the $A_{1}$ site as usual for lanthanides in TTB structures, decreasing its occupancy in the $\mathrm{C}$ site. Refinement and atomic parameters are reported in Tables 1 and 2, respectively; selected bond lengths are reported in Table 3 . In the Tables 2 and 3 we have indicated with $\operatorname{Pr} 1$ and $\operatorname{Pr} 2$ the $\operatorname{Pr}^{3+}$ ions located at the $\mathrm{A}_{1}$ and $\mathrm{C}$ sites, respectively. The distribution of $\operatorname{Pr}^{3+}$ over the two sites influences the shortest $\mathrm{Pr}-\mathrm{Nb}$ distance that represents a critical spectroscopic parameter. The average $\mathrm{Pr}-\mathrm{Nb}$ shortest distance, determined for the three samples and weighted on the refined site occupancy (Table 3), is in good agreement with the values predicted from the spectroscopic behaviour, indicating the effectiveness of the proposed model.

\section{Conclusions}

The luminescence spectra of Pr:BNN crystals are influenced by the host properties and by the substitution mechanisms. Measurements as a function of the temperature, of the excitation wavelength and of the doping level have evidenced the presence of non equivalent optical centres whose emission properties are affected by different and concomitant non radiative processes. The interaction between host and doping ions results in the formation of an IVCT state that actively participates to the excited states dynamics of the system. In this context, the concentration shift of the IVCT band has been accounted for on the basis of a previously developed empirical model that allows formulating a hypothesis about the site occupancy of the $\operatorname{Pr}^{3+}$ ion in this host. The structures of the investigated materials have been determined by single crystal XRD measurements and are consistent with the supposed $\operatorname{Pr}^{3+}$ occupancy, and the connection with the growth procedure has been pointed out.

\section{References}

1. R. R. Neurgaonkar, W. K. Cory, J. Opt. Soc. Am. B 3 (1986) 274.

2. G. Foulon, A. Brenier, M. Ferriol, M. T. Cohen-Adad, G. Boulon, Chem. Phys. Lett. 249 (1996) 381.

3. A. Rodenas, D. Jaque, F. Agulló-Rueda, A.A. Kaminskii, Opt. Comm. 262 (2006) 220.

4. F. Carrillo-Romo, C. Goutaudier, Y. Guyot, M. T. Cohen-Adad, G. Boulon, K. Lebbou, A. Yoshikawa, T. Fukuda, Opt. Mat. 16 (2001) 199.

5. S. Bigotta, G. Gorini, A. Toncelli, M. Tonelli, E. Cavalli, E. Bovero, Opt. Mat. 28 (2006) 395.

6. S. Bigotta, A. Toncelli, M. Tonelli, E. Cavalli, E. Bovero, Opt. Mat. 30 (2006) 129.

7. S. Bigotta, M. Tonelli, E. Cavalli, J. Phys.: Condens. Matter 19 (2007) 476208.

8. E. Cavalli, A. Belletti, R. Mahiou, P. Boutinaud, J. Lumin. 130 (2010) 733

9. R. Naccache, F. Vetrone, A. Speghini, M. Bettinelli, J. A. Capobianco, J. Phys. Chem. C 112 (2008) 7750.

10. H. R. Xia, L. X. Li, H. Yu, X. L. Meng, L. Zhu, L. J. Hu, Cryst. Res. Tech. 34 (1999) 901.

11. M. Bettinelli, A. Speghini, A. Ródenas, P. Molina, M. O Ramírez, B. Capote, D. Jaque, L. E. Bausá, J. García Solé, J. Lumin. 122-123 (2007) 307.

12. P. Boutinaud, E. Cavalli, M. Bettinelli, J. Phys. Condens. Matter 19 (2007) 386230.

13. Nakazawa, E. Phosphor Handbook; CRC Press: Boca Raton, FL, 1999.

14. A. Altomare, M. C. Burla, M. Camalli, G. Cascarano, C. Giacovazzo, A. Guagliardi, A. G. G. Moliterni, G. Polidori, R. Spagna, SIR2002, Program for Crystal Structure Solution and Refinement; IRMEC-CNR, Bari, Italy, 2002.

15. G. M. Sheldrick, SHELXL97, Program for Crystal Structure Refinement; University of Gottingen, Germany, 1993.

16. P. B. Jamieson, S. C. Abrahams, J. L. Bernstein, J. Chem. Phys. 50 (1969) 4352.

17. P. Ju Lin, L. A. Bursill, Acta Crystallogr. B 43 (1987) 504.

18. P. Labbé, H. Leligny, B. Raveau, J. Scheck, J. C. Toledano, J. Phys. Condens. Matter 2 (1989) 25.

19. S. Fabbrici, E. Montanari, L. Righi, G. Calestani, A. Migliori, Chem. Mater. 16 (2004) 3007. 
20. F. Mezzadri, S. Fabbrici, E. Montanari, L. Righi, G. Calestani, E. Gilioli, F. Bolzoni, and A. Migliori, Phys. Rev. B 78 (2008) 064111. 